Article

\title{
Sorting Liquid Droplets by Surface Tension Using Devices with Quasi-Superamphiphobic Coatings
}

\author{
Yu-Ping Zhang ${ }^{1,2, *}$, Di Fan ${ }^{1}$, Xiu-Zhi Bai ${ }^{1}$, Cheng-Xing Cui ${ }^{1}$, Jun Chen ${ }^{1}$, Ren-Long Li ${ }^{1}$, \\ Peng-Fei Liu ${ }^{1}$ and Ling-Bo $Q u^{2}$ \\ 1 Henan Institute of Science and Technology, Xinxiang 453000, China; ccxcyh@gmail.com (D.F.); \\ amibai@126.com (X.-Z.B.); chengxingcui@hist.edu.cn (C.-X.C.); junchen713@126.com (J.C.); \\ rlli@hist.edu.cn (R.-L.L.); lpf8856@163.com (P.-F.L.) \\ 2 College of Chemistry and Molecular Engineering, Zhengzhou University, Zhengzhou 450001, China; \\ qulingbo@zzu.edu.cn \\ * Correspondence: zhangyuping@hist.edu.cn
}

Received: 12 March 2020; Accepted: 30 March 2020; Published: 4 April 2020

check for updates

\begin{abstract}
Any solid surface with homogenous or varying surface energy can spontaneously show variable wettability to liquid droplets with different or identical surface tensions. Here, we studied a glass slide sprayed with a quasi-superamphiphobic coating consisting of a hexane suspension of perfluorosilane-coated nanoparticles. Four areas on the glass slide with a total length of $7.5 \mathrm{~cm}$ were precisely tuned via ultraviolet (UV) irradiation, and droplets with surface tensions of $72.1-33.9 \mathrm{mN} \mathrm{m}^{-1}$ were categorized at a tilting angle of $3^{\circ}$. Then, we fabricated a U-shaped device sprayed with the same coating and used it to sort the droplets more finely by rolling them in the guide groove of the device to measure their total rolling time and distance. We found a correlation between ethanol content/surface tension and rolling time/distance, so we used the same device to estimate the alcoholic strength of Chinese liquors and to predict the surface tension of ethanol aqueous solutions.
\end{abstract}

Keywords: surface energy; quasi-superamphiphobic surface; Chinese liquors

\section{Introduction}

Inspired by the self-cleaning and water-repellent properties of plants and animals such as lotus leaves [1,2], red rose petals [3], water striders [4,5], and butterflies [6], superhydrophobic and superoleophobic materials have drawn considerable attention in both academic and industrial settings. Hierarchical structures made with low-surface-energy materials can produce surfaces with large static contact angles $\left(\mathrm{SCAs}>150^{\circ}\right)$ to water droplets $\left(\gamma_{\mathrm{lv}}=72.1 \mathrm{mN} \mathrm{m}^{-1}\right.$, a representative high- $\gamma_{\mathrm{lv}}$ liquid). Those that exhibit high SCAs $\left(>150^{\circ}\right)$ and low rolling angles (RAs $<10^{\circ}$ ) to oils (organic liquids) are called superoleophobic surfaces [7]. Surfaces that can repel both water and oils $\left(\gamma<30 \mathrm{mN} \mathrm{m}^{-1}\right)$ are called superamphiphobic surfaces, which typically have a topography that traps air in pockets [8]. Since organic liquids with lower surface tension can easily spread on many solid substrates, fabricating superamphiphobic surfaces is challenging. Superamphiphobic surfaces are most often produced using chemical etching and plasma treatments [9-12], though other methods such as electrodeposition [13], spraying [14], and photolithography [15] have been used to coat various substrates such as metals, textiles, and membranes [16-18].

Any solid surface with homogeneous or varying surface energy can spontaneously exhibit different wettability toward liquid droplets with different or identical surface tensions $(\gamma)$. Considering the correlation between wettability and liquid surface tension on solid surfaces, some typical applications include sorting droplets by surface tension as well as estimating the organic concentration and surface tension of organic aqueous solutions [19-21]. For example, Kota et al. etched a titanium sheet and 
fabricated a superomniphobic coating with fluorinated, flower-like $\mathrm{TiO}_{2}$ nanostructures [22], tuned the sheet's surface energy by ultraviolet (UV) irradiation, and used it to categorize droplets by surface tension over a wide range of concentrations (0-60\% ethanol aqueous solutions). The droplets with the lowest surface tension for $60 \%$ ethanol aqueous solution $\left(28.7 \mathrm{mN} \mathrm{m}^{-1}\right)$ ceased at domain 1 due to strong adhesion, and droplets with surface tensions in the range of $37.2-72.1 \mathrm{mN} \mathrm{m}^{-1}$ were sorted. Huang et. al recently fabricated a superamphiphobic surface by spraying an ethanol suspension with two sizes of $\mathrm{TiO}_{2}$ nanoparticles and perfluorosilane [23]. Their tuned glass with a gradient of solid surface energy or wettability could sort six droplets of ethanol with different concentrations $(0-35 \%)$ or surface tensions. Moreover, droplets with different concentrations of adenosine triphosphate (ATP) were effectively sorted by the surface after ATP-dependent rolling circle amplification (RCA). Recently, Wang et al. reported a new way to prepare one-way oil-transport fabrics coated with flowerlike $\mathrm{ZnO}$ nanorods, fluorinated decyl polyhedral oligomeric silsesquioxanes, and hydrolyzed fluorinated alkylsilane [24]. Changing the irradiation time from $6 \mathrm{~h}$ to $30 \mathrm{~h}$ broadened the one-way transport of droplets with surface tensions of $22.3-56.7 \mathrm{mN} \mathrm{m}^{-1}$. This versatile method estimated the surface tension of a liquid simply by observing its motion on a series of fabrics with different one-way oil-transport selectivity. Later, robust and transparent superhydrophobic surfaces were produced using acid-and base-catalyzed silica particles combined with a candle soot template and chemical vapor deposition (CVD) for chemical modification [25]; three porous silica structures were created that showed different surface tension responsiveness in wettability.

In the current paper, we fabricated a quasi-superamphiphobic coating by spraying a hexane suspension of perfluorosilane-coated nanoparticles onto a glass slide as well as onto a rolling groove with a semi-circular arc. The glass slide was divided into four areas with a total length of $\sim 7.5 \mathrm{~mm}$, and its surface energy and contact angle hysteresis (i.e., the difference between the advancing and receding contact angles) were adjusted in each area by changing the UV irradiation time up to $2 \mathrm{~h}$. The four areas, with identical surface texture but different solid surface energy, allowed high-surface-tension droplets to roll past while trapping low-surface-tension droplets due to adhesion. For comparison, we dropped the same droplets into the guide groove of a semi-circular arc with a diameter of $7 \mathrm{~cm}$, with the same coating, and let these droplets roll back and forth. By measuring their total rolling time or distance, we differentiated the ethanol aqueous solutions with different surface tensions with good reproducibility. In short, we produced a portable device with a super-repellent surface that can sort droplets without tuned areas of solid surface energy. This device is particularly useful for estimating the ethanol volume percentage, namely the alcohol strength (AS), and surface tension of ethanol aqueous solutions such as Chinese liquors in the field.

\section{Experimental Section}

\subsection{Preparation of Quasi-Superamphiphobic Surfaces}

Glass slides ( $75 \mathrm{~mm}$ long $\times 25 \mathrm{~mm}$ wide $\times 3 \mathrm{~mm}$ thick) were cleaned by sonication in acetone and deionized water thoroughly and dried with nitrogen. Herein, a facile procedure to modify the glass slide by spraying method was attempted. Considering that the wettability of the surface is controlled by the chemical composition and the surface roughness, we added $\mathrm{SiO}_{2}$ or $\mathrm{TiO}_{2}$ nanoparticles together with one silane coupler of tetraethyl orthosilicate (TEOS) to increase the surface hydrophobicity and roughness. Trichloro $(1 \mathrm{H}, 1 \mathrm{H}, 2 \mathrm{H}, 2 \mathrm{H}$-tridecafluoro-n-octyl) silane (FOTS) was added as a coupler for the decrease of low-surface-energy on the surface. The suspension consisted of $1 \%$ FOTS, and/or 1\% TEOS, and/or $1 \% \mathrm{SiO}_{2}$ and $3 \% \mathrm{TiO}_{2}$ nanoparticles in $10 \mathrm{~mL}$ hexane mixtures. The uniform suspension was coated on the pretreated glass and U-shaped device carefully by a spray gun (Lotus, Shanghai, China) with a $0.8-\mathrm{mm}$ nozzle diameter by using a nitrogen pressure of $0.3 \mathrm{MPa}$. Then, the painted glass and U-shaped device were air dried horizontally. 


\subsection{Measurement of Surface Tension, Contact Angles, and Roll Off Angles}

Surface tension measurements were carried out at room temperature by the pendent drop method using a contact angle goniometer (TST-200, Shen Zhen Testing Equipment Co.LTD, Shen Zhen, China). Results were expressed as $\mathrm{mN} / \mathrm{m}$ and are the mean value of triplicate analyses. The contact angles and roll-off angles were measured using the same instrument. The contact angles were measured by advancing or receding $10 \pm 0.5 \mu \mathrm{L}$ droplets on the surface using a micrometer syringe. The roll-off angles were measured by tilting the platform until the $10 \pm 0.5 \mu \mathrm{L}$ droplets rolled off from the surface of the glass slide. At least six measurements were performed on each glass slide.

\subsection{Tuning Surface Chemistry and Solid Surface Energy via UV Irradiation}

Devices with discrete solid surface energy domains were fabricated by UV light irradiating the desired area of the fabricated quasi-superomniphobic surface for the desired time. An XL-1500 UV cross-linker (Spectronics Corp., Westbury, NY, USA), equipped with six 15 W blacklight tubes, was used; one domain of the fabricated glass slides was irradiated at a wavelength of $365 \mathrm{~nm}$ while the other domains were masked with a substrate mask. The advancing contact angles measured at different UV irradiation times on fluorinated glass surfaces were used to estimate the solid surface energy by the Fowkes method.

\subsection{Characterization of Surface Morphology, Roughness, and Chemical Composition}

The surface morphologies of the sprayed glass slides were characterized by scanning electron microscope (SEM, FEI Company, Hillsboro, OR, USA). The surface topography and nanoscale asperities were measured using a three-dimensional (3D) surface profilometer. The roughness of the surfaces was measured using an optical profilometer (GTK-16-0300, Bruker Scientific Company, Waltham, MA, USA). At least three measurements were performed on each surface. The surface element and composition of coating was measured by X-ray photoelectron spectroscopy (XPS, Thermo Fisher, Waltham, MA, USA).

\subsection{Calculation of the Rolling Distance}

The rolling process was videoed and played back by a HUAWEI smart phone (Shenzhen, China) in slow motion mode. Each rolling track was recorded according to the angle mark on the side of the device. The total angles were added according to the marked points (the start point, the top points, and the last end point) that the droplet rolled back and forth along the guide groove.

\section{Results and Discussion}

A mixture of a $10 \mathrm{~mL}$ hexane suspension was prepared and mixed fully by a vortex oscillator for $30 \mathrm{~min}$, containing $1 \%(\mathrm{v} / \mathrm{v})$ trichloro $(1 \mathrm{H}, 1 \mathrm{H}, 2 \mathrm{H}, 2 \mathrm{H}$-tridecafluoro-n-octyl)silane (FOTS), $1 \%(\mathrm{v} / \mathrm{v})$ tetraethyl orthosilicate (TEOS), $1 \%(w / v) \mathrm{SiO}_{2}(20-40 \mathrm{~nm})$, and/or 3\% $(w / v) \mathrm{TiO}_{2}$ nanoparticles $(\sim 21 \mathrm{~nm})$. To prepare the super-repellant surface, we optimized various suspension solutions (Nos. 1-5) by step-by-step addition of active FOTS, TEOS, $\mathrm{SiO}_{2}$, and $\mathrm{TiO}_{2}$ nanoparticles in different amounts. contact angles (CAs) in the range of $138-152^{\circ}$ appeared for the deionized water $\left(\gamma_{\mathrm{lv}}=72.1 \mathrm{mN} \mathrm{m}^{-1}\right)$ and $30-144^{\circ}$ for the $30 \%$ ethanol aqueous solution $\left(\gamma_{\mathrm{lv}}=37.2 \mathrm{mN} \mathrm{m}^{-1}\right)$ (see Figure 1). The glass slide sprayed with the No. 5 suspension solution showed optimal liquid repellence, with rolling angles of $1.3^{\circ}$ and $2.9^{\circ}$ for water and the $30 \%$ ethanol solution, respectively. This coating still repelled water even after being immersed in oil (hexane), and it showed water jetting and water droplets bouncing on the quasi-superhydrophobic surface with no residual adhesion on the glass slide (see Video S1). On this surface, both water and 30\% ethanol were primarily in the Cassie-Baxter state, which agrees with our previous study on laboratory filter paper [26].

As shown by scanning electron microscopy, our quasi-superamphiphobic coating exhibited nano/micro structures, produced from the adherence between FOTS/TEOS and both nanoparticles with different sizes (see Figure 2a,b). Slide No. 5 had an average roughness $\left(R_{\mathrm{a}}\right)$ of $9.1 \pm 0.1 \mu \mathrm{m}$ (Figure 2c). 
Elemental analysis found Ti 2p, Si 2p, C 1s, O 1s, and F 1s on the surface of the glass slide (Figure 2d). The Ti $2 p$ high-resolution spectrum was deconvoluted into peaks at $460 \mathrm{eV}$ (Ti 2p 1/2) and $458.6 \mathrm{eV}$ (Ti $2 \mathrm{p} 3 / 2$ ), indicating $\mathrm{TiO}_{2}$. The $\mathrm{Si} 2 \mathrm{p}$ peak appeared at a binding energy of $104 \mathrm{eV}$, referring to $\mathrm{Si}$, and the $C 1$ s profile was characterized by two typical peaks at 287 and $292 \mathrm{eV}$. In addition, the $\mathrm{O} 1 \mathrm{~s}$ profile was characterized by two typical peaks at 534 and $531 \mathrm{eV}$ (see Figure 2d). The elemental atomic contents were $1.75 \%$ Ti 2 p, $15.8 \%$ Si 2 p, $18.5 \%$ C 1s, 31.7\% O 1s, and $32.3 \%$ F 1 s.

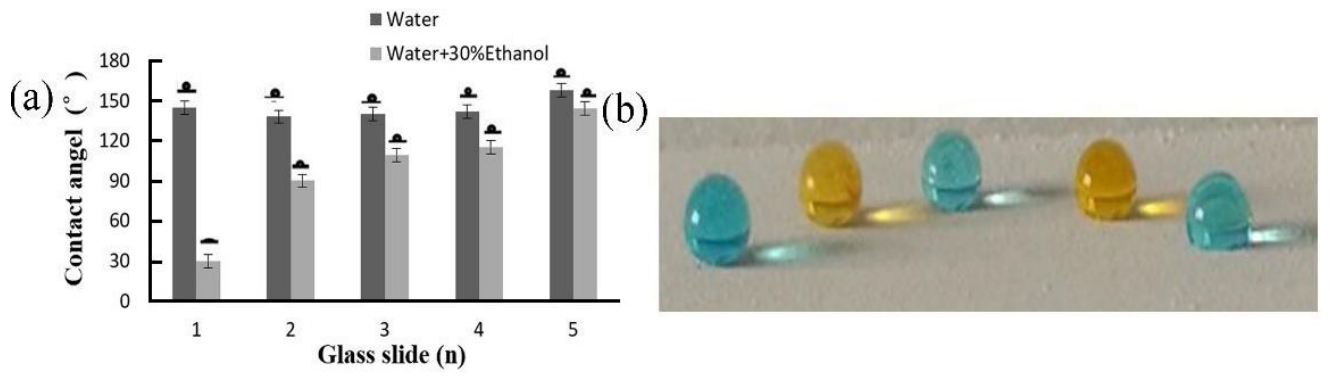

(c)
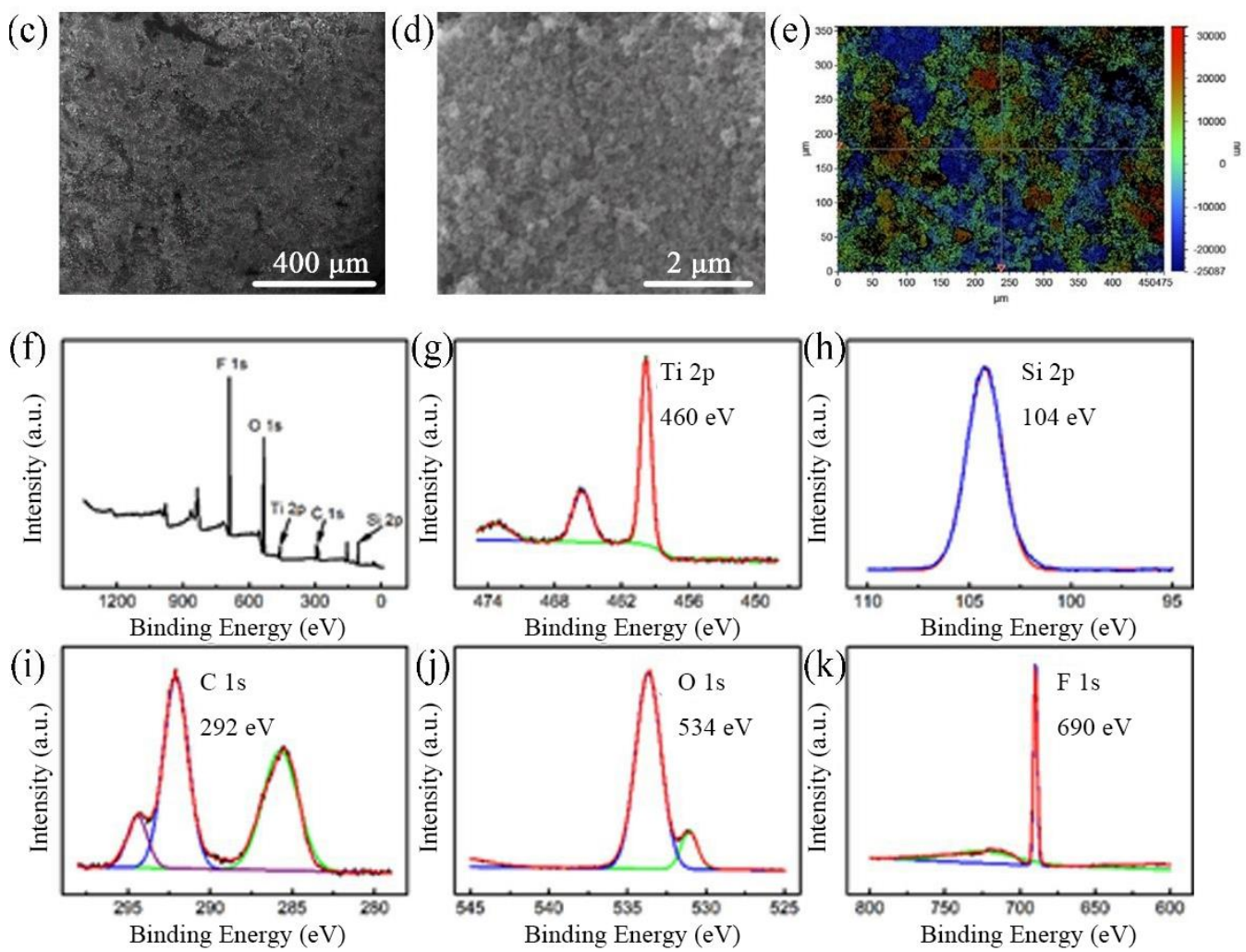

Figure 1. (a) Contact angles (CAs) of water and 30\% ethanol on glass surfaces treated with various coatings: (1) $1 \%$ trichloro $\left(1 \mathrm{H}, 1 \mathrm{H}, 2 \mathrm{H}, 2 \mathrm{H}\right.$-tridecafluoro-n-octyl) silane (FOTS) $+1 \%$ nano $\mathrm{SiO}_{2} ;$ (2) $1 \%$ FOTS $+1 \%$ tetraethyl orthosilicate (TEOS) $+3 \% \mathrm{TiO}_{2}$; (3) $1 \%$ FOTS $+1 \%$ nano $\mathrm{SiO}_{2}+3 \% \mathrm{TiO}_{2}$; (4) $1 \%$ FOTS $+1 \%$ nano $\mathrm{SiO}_{2}+1 \%$ TEOS; (5) $1 \%$ FOTS $+1 \%$ nano $\mathrm{SiO}_{2}+1 \% \mathrm{TEOS}+3 \% \mathrm{TiO}_{2}$. (b) Images of the droplets of ethanol aqueous solutions on the quasi-superamphiphobic surface of Slide No. 5. Droplets (from left to right) of water, water $+10 \%$ ethanol, water $+20 \%$ ethanol, water $+30 \%$ ethanol, and water $+40 \%$ ethanol $\left(\gamma_{l v}=33.9 \mathrm{mN} \mathrm{m}^{-1}\right)$, showing gradually decreasing apparent contact angles on the quasi-superamphiphobic surface. (c-d) Scanning electron microscopy images showing the morphology of the optimal glass slide, Slide No. 5. (e) Roughness mapping with a $R_{\text {rms }}$ of $9.1 \pm 0.1 \mu \mathrm{m}$. (f) X-ray photoelectron spectroscopy (XPS) survey spectra of Slide No. 5. (g-k) XPS core level spectra of Ti 2p, Si 2p, C 1s, O 1s, and F 1s peaks.

We tailored the resulting quasi-superamphiphobic glass slide by shining UV light on four areas. The photocatalytic activity of $\mathrm{TiO}_{2}$ in the coating allowed us to precisely tune the solid surface energy. 
After UV irradiation, the $\mathrm{TiO}_{2}$ nanoparticles generated holes that readily reacted with lattice oxygen, creating surface oxygen vacancies. These vacancies coordinated to water molecules in air, which increased the surface hydrophilicity $[27,28]$. Here, areas $2-4$ were irradiated for 70, 90, and $110 \mathrm{~min}$, respectively, while area 1 was not irradiated. With increasing UV irradiation time, the solid surface energy increased from area $1\left(0.24 \mathrm{mN} \mathrm{m}^{-1}\right)$ to area $4\left(1.49 \mathrm{mN} \mathrm{m}^{-1}\right)$, determined by the Fowkes method (Figure S1) $[29,30]$. Likewise, with increasing UV irradiation time, the apparent contact angles gradually decreased and the contact angle hysteresis increased for both water and the four ethanol aqueous solutions (Figure 2a,b). The measured roll-off angles of the $10 \mu \mathrm{L}$ ethanol solution droplets with less surface tension on the glass slide increased faster than those of the $10 \mu \mathrm{L}$ water droplets.

The tilted glass slide sorted droplets based on a balance between the work done by gravity and the work expended by adhesion, as described in Equation (1) [22,23]:

$$
V \rho \operatorname{gsin} \omega \approx \gamma_{l v} D_{\mathrm{TCL}}\left(\cos \theta_{\text {rec }}^{*}-\cos \theta_{\text {adv }}^{*}\right)
$$

where $V$ is the volume of the droplet, $\rho$ is the liquid density, $g$ is the acceleration of gravity, and $\omega$ is the roll-off angle of the droplet. $D_{\mathrm{TCL}}$ is the width of the solid-liquid-vapor contact line perpendicular to the rolling direction, $\theta^{*}{ }_{r \text { ec }}$ and $\theta^{*}$ adv are the apparent receding and advancing contact angles, and $\gamma_{l v}$ is the surface tension of the liquid on the solid surface. Thus, droplets with certain higher surface tension should roll-off the solid surface with a certain surface energy $\gamma_{\mathrm{sv}}$ and appropriate inclination angle $\alpha$ (here, $\omega<\alpha$ ), while droplets with lower surface tension and $\omega>\alpha$ will be trapped on the corresponding areas.

The surface tensions of various ethanol aqueous solutions $(0-40 \%)$ were determined by the pendant drop method [31-33] and selected for droplet sorting. We estimated the roll-off angles for five $10 \mu \mathrm{L}$ droplets in each of the four areas by measuring their $\theta^{*}$ rec and $\theta^{*}$ adv (Table S1). Based on the estimated roll-off angles (Figure 2c), when Slide No. 5 is set at an angle $\alpha=3^{\circ}$, droplets of the $40 \%$ ethanol aqueous solution $\left(\gamma_{l v}=33.9 \mathrm{mN} \mathrm{m}^{-1}\right)$ should get trapped in area 1 ; droplets of $30 \%$ ethanol $\left(\gamma_{l v}=37.8 \mathrm{mN} \mathrm{m}^{-1}\right)$ should roll past area 1 but get trapped in area 2; droplets of water $+20 \%$ ethanol $\left(\gamma_{l v}=44.8 \mathrm{mN} \mathrm{m}^{-1}\right)$ should roll past areas 1 and 2 but get trapped in area 3 ; droplets of water $+10 \%$ ethanol $\left(\gamma_{l v}=51.4 \mathrm{mN} \mathrm{m}^{-1}\right)$ should roll past areas 1,2, and 3 but get trapped in area 4 ; and droplets of water $\left(\gamma_{l v}=72.1 \mathrm{mN} \mathrm{m}^{-1}\right)$ should roll past all areas. These predictions matched reasonably well with our experimental results shown in Figure $3 \mathrm{c}$,d. The whole process to sort five droplets using the tuned glass slide at a tilt angle of $3^{\circ}$ (based on the estimated roll-off angles) is shown in Figure $3 \mathrm{~d}$ (also see Video S2). Five droplets, with surface tensions of $33.9-72.1 \mathrm{mN} \mathrm{m}^{-1}$, were sorted on the four areas but with limited resolution and discrimination. That is, the droplets with similar surface tensions were difficult to sort without tuning the solid surface energy further. For example, the droplets of the $5 \%$ ethanol aqueous solution and the $10 \%$ ethanol solution rolled off and were both trapped in area 4 , showing less discrimination and reproducibility $[22,23]$.

Thus, we improved the discrimination degree by using a U-shaped analytical device treated with identical coating, sorting droplets with surface tensions of $33.9-72.1 \mathrm{mN} / \mathrm{m}$ according to their motion as they rolled back and forth in the guide groove (Figure 3a). 


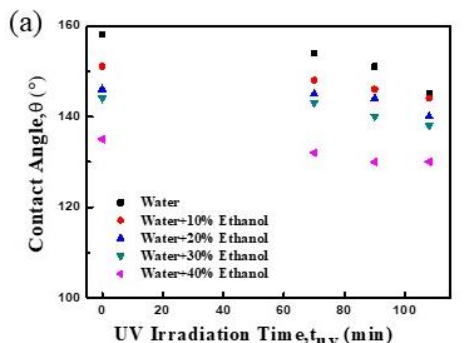

UV Irradiation Tim e, $\mathbf{u}_{\mathbf{v}}(\mathrm{min})$ (b)

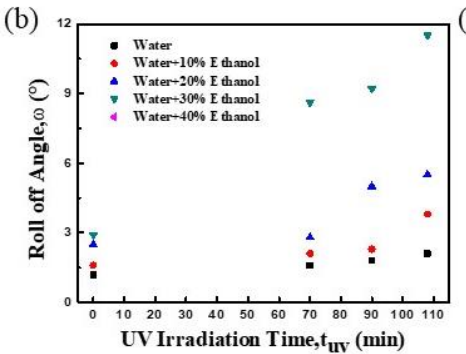

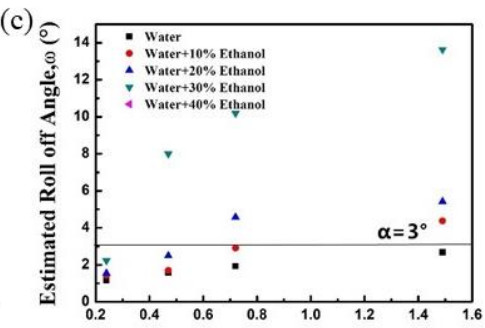

Surface Energy, $\gamma_{\mathrm{sv}}(\mathrm{mN} / \mathrm{m})$

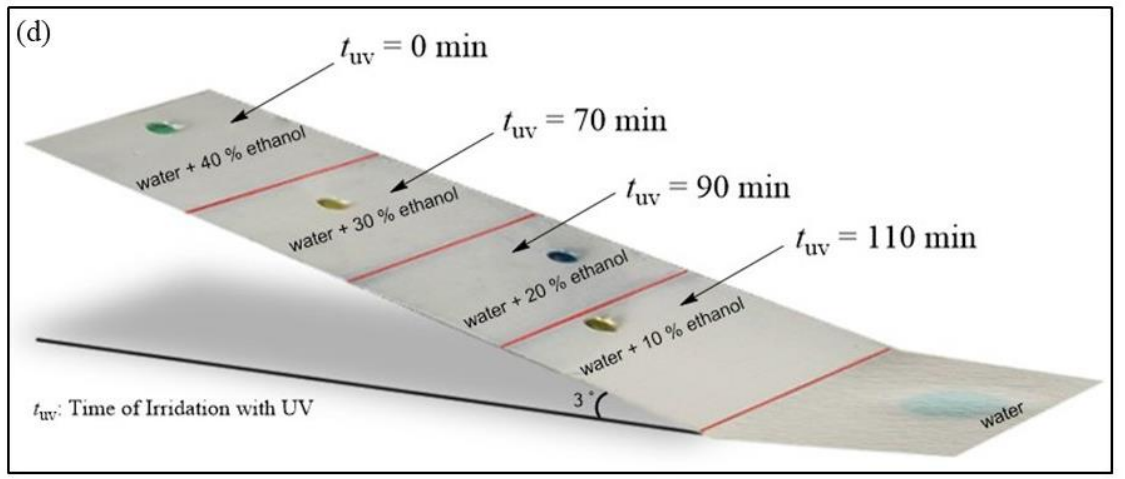

Figure 2. (a) Apparent contact angles of droplets on Slide No. 5, decreasing with increasing ultraviolet (UV) irradiation time. (b) Measured roll-off angles of $10 \mu \mathrm{L}$ ethanol solution droplets on the slide increased faster than those of $10 \mu \mathrm{L}$ water droplets with increasing UV irradiation time. (c) Estimated roll-off angles of various $10 \mu \mathrm{L}$ droplets on the slide with different solid surface energies. (d) Schematic showing the sorting of $10 \mu \mathrm{L}$ droplets using the slide tilted at $3^{\circ}$ with four areas of different surface energy. 
(a)
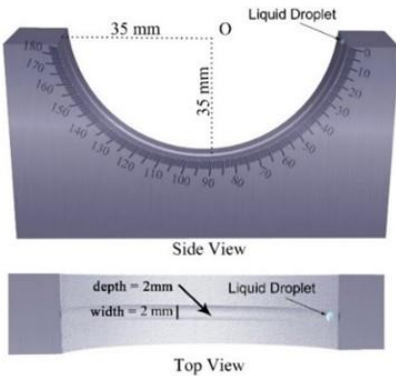

(c) $)^{35}$

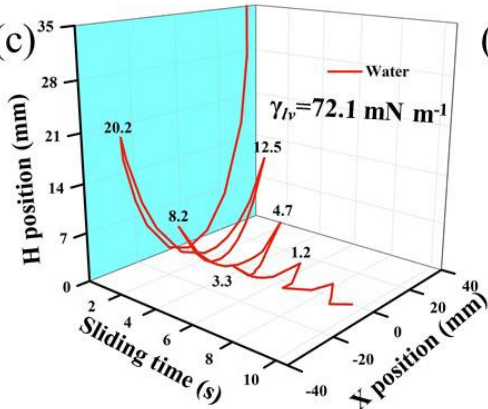

(e)

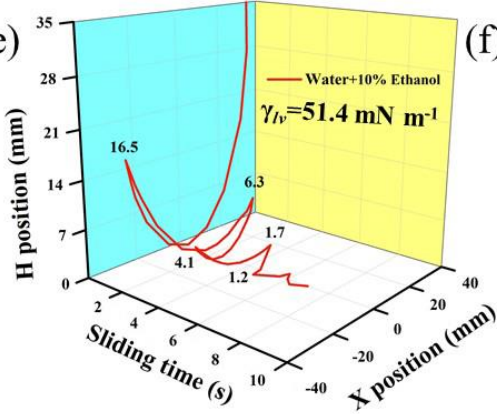

(g)

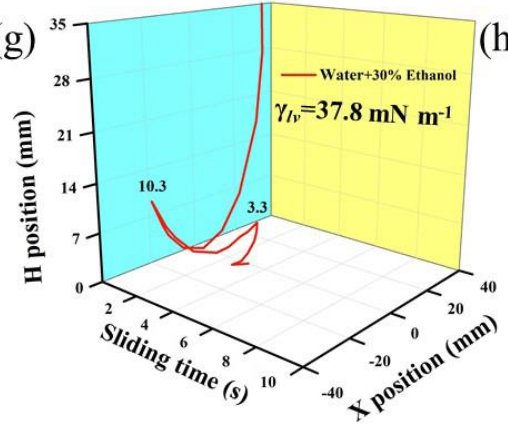

(b)

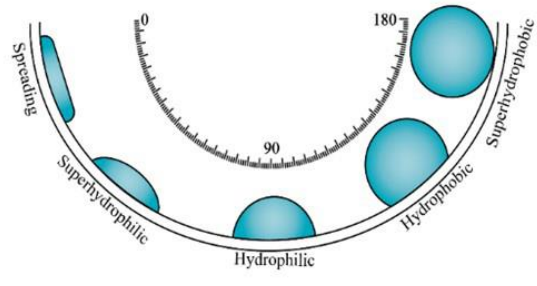

(d)

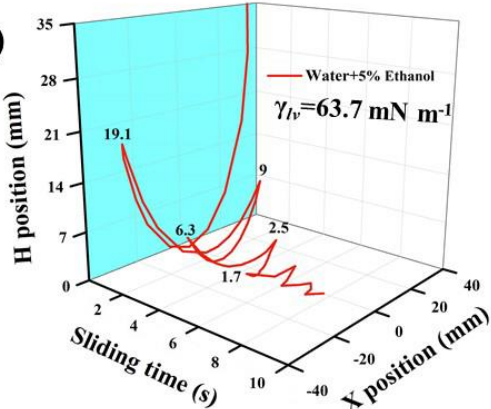

(f)

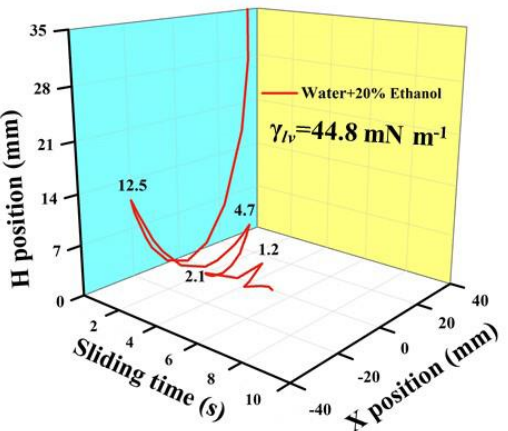

(h)

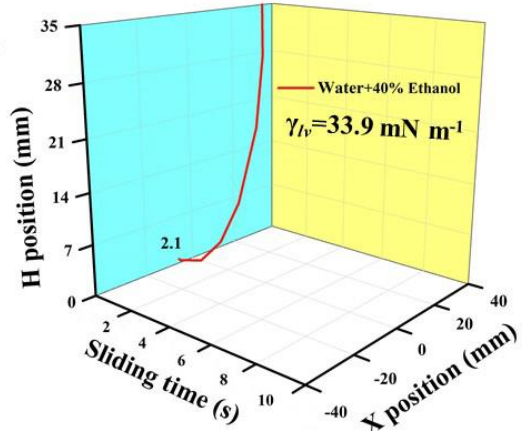

Figure 3. (a) Side and top views of our device for droplet sorting, surface tension estimation, and AS prediction. (b) Images of droplets with various surface tensions in the guide groove. (c-h) Schematics showing the fine sorting of droplets by surface tension using our device and measuring their rolling time or distance.

By recording the entire motion of a droplet along the guide groove in slow motion with a smartphone, we calculated its total rolling time and distance. In calculating the total distance, by marking the highest position each time the droplet moved back and forth in the groove, the total rolling or sliding angle $(\mathrm{A} 1+\mathrm{A} 2+\mathrm{A} 3+\ldots+\mathrm{An})$ could be added together to calculate the total rolling distance $(\mathrm{D}, \mathrm{mm})$ as

$$
\mathrm{D}=\frac{(\mathrm{A} 1+\mathrm{A} 2+\cdots \mathrm{An}) \times 2 \pi \times \mathrm{R}}{360^{\circ}}
$$


where A1, A2 ... An are the rolling angles along the circular arc for the first, second, and $n$ time, respectively, and $\mathrm{R}$ is the radius of the semi-circular metal platform.

Water droplets of various volumes $(5-50 \mu \mathrm{L})$ were dropped in the guide groove, and the total rolling time and distance was recorded in ranges of 6-23 s and 209-701 mm, respectively. Further increasing the droplet volume caused the droplet to roll out of the guide groove unexpectedly. The droplet volume correlated well to the rolling time and distance, with correlation coefficients (R) of 0.9980 and 0.9897, respectively (Figures S2 and S3). Thus, the droplets could be sorted over a wider range of surface tensions by increasing the droplet volume.

Generally, $10 \mu \mathrm{L}$ droplets of various ethanol aqueous solutions (0-40\%) were carefully dispensed into the guide groove from the top of the U-shaped analytical device using a syringe capped with a hydrophobic needle. The droplet slides along the guide groove from the top, rolls across the lowest point in the groove, and rolls up to the first highest point along the groove. After rolling back and forth several times, the droplet finally stops somewhere in the groove, most often at the bottom. Droplets with less surface tension slide for less time and distance due to stronger adhesion. The change of the droplet potential energy remains as the sum of the energy dissipation and kinetic energy change during the droplet rolling back and forth in the guide groove. Therefore, it satisfies the equation $\Delta \mathrm{E}_{\text {total }}=\Delta \mathrm{E}_{\text {loss }}+\Delta \mathrm{E}_{\text {kinetic, }}$, where $\Delta \mathrm{E}_{\text {total }}\left(\Delta \mathrm{E}_{\text {total }}=\mathrm{mg} \Delta \mathrm{h}\right.$, where $\mathrm{m}$ is the mass of the droplet, $\mathrm{g}$ is the gravitational acceleration, and $\Delta \mathrm{h}$ is the elevation between the droplet location and the lowest point in the guide groove) represents the potential energy change of the droplet along the arc hydrophobic surface. $\Delta \mathrm{E}_{\text {loss }}$ is the dissipation energy, which is created by deformation force of the droplet, adhesion force, shear force, and air-drag force during the movement of the liquid droplet [34]. For the liquid droplets with larger surface tension, it is easily understood that it can move easily on the superhydrophobic surface with less $\Delta \mathrm{E}_{\text {loss }}$; thus, larger $\Delta \mathrm{E}_{\text {kinetic }}$ will drive the liquid droplet to move a longer time or distance along the groove $[20,35]$.

Droplets rolled from the top (about $35 \mathrm{~mm}$ above the bottom of the groove), rolled across the bottom, then rolled up to the first highest point ( $20.2 \mathrm{~mm}$ above the bottom). The water droplet that rolled for the longest time and distance rolled back and forth about 10 times with a distance of $359 \mathrm{~mm}$ over $10 \mathrm{~s}$. As the ethanol concentration gradually increased to $40 \%$, the rolling time and distance decreased to $1.5 \mathrm{~s}$ and $67 \mathrm{~mm}$, respectively (see Video S3).

Using this simple operation, we sorted the six droplets by surface tensions of $33.9-72.1 \mathrm{mN} \mathrm{m}^{-1}$. Compared with our tuned glass slide and previous reports with a rolling length of 60-75 $\mathrm{mm}$ [22,23], we obtained higher resolution and discrimination, with rolling distances in the range of $67-359 \mathrm{~mm}$. That is, we sorted the droplets with closer surface tensions and over a wider range of surface tensions using our device. More importantly, we sorted the droplets by rolling time in a range of 1.5-10.1 s by simply recording them in slow motion (1/4 normal speed) with a smartphone.

The rolling motions of the droplets are illustrated in the simulated 3D diagram shown in Figure 3. Six droplets with different surface tensions were differentiated by rolling time, rolling distance, number of rolling cycles, and the first highest position. As the surface tension gradually decreased from $72.1 \mathrm{mN} \mathrm{m}^{-1}$ to $33.9 \mathrm{mN} \mathrm{m}^{-1}$, the first highest position gradually decreased from $20.2 \mathrm{~mm}$ to $2.1 \mathrm{~mm}$. Each droplet was rolled eight times, and the relative standard derivation (RSD) of the total rolling distance was less than $1 \%$ (Table S2). These results show that the sprayed coating was not damaged after rolling droplets with surface tensions of $33.9-72.1 \mathrm{mN} \mathrm{m}^{-1}$ many times, and this stable surface could be used for rolling over 100 times without an apparent decrease in reproducibility. However, the coating gradually was deteriorated by infiltration of a droplet with a surface tension lower than $30 \mathrm{mN} \mathrm{m}^{-1}$, because the stronger adhesion of this droplet decreased the reproducibility of the rolling time and distance.

Thus, the relationship between the rolling time/distance and ethanol volume content was computed. Chinese liquors mostly consist of ethanol and water with trace flavor additives, so they can be regarded as typical ethanol-water mixtures, with their alcohol strength (AS) expressed in an ethanol volume percent by total volume, estimated according to their rolling time or distance. Using a standard 
regression curve, we estimated the AS and surface tension of some samples of real Chinese liquors. Here, Chinese liquors of Jinjiu (labeled AS of 35\%) and Maotai Wangzhi (labeled AS of 52\%) were diluted to various concentrations. We tested three diluted Jinjiu samples with AS values of $20 \%, 30 \%$, and $35 \%$ as well as three diluted Maotai samples with AS values of $10.6 \%, 21.2 \%$, and $31.8 \%$, respectively.

After determining or calculating the rolling time and distance for $10 \mu \mathrm{L}$ droplets of these liquors, the estimated AS results agreed well with the labeled AS values, and we could predict about $80 \%$ the AS values of these samples based only on rolling time or distance (see Table S3). The correlation between alcohol strength (AS) and $T_{\text {total }}$ was obtained as $=0.1383 T^{2}-6.1804 T+49.894$, with a regression coefficient $(R)$ of 0.9836 (see Figure S4). In addition, the correlation between AS and $D_{\text {total }}$ was obtained as AS $=0.0063 D^{2}-1.7306 D+52.569$, with a regression coefficient $(R)$ of 0.9880 (see Figure S5).

Simulated tracks of the real liquor samples are also illustrated (see Figure S6), and the diluted liquors were recorded while rolling to compare them with standard solutions of similar ethanol volume contents (see Video S4). Similar rolling times and cycle numbers appeared, indicating the potential of predicting the relative AS values. Moreover, the surface tensions $\left(\gamma_{\mathrm{lv}}\right)$ of the selected six liquors were calculated using regression equations based on rolling time and distance (see Figures S7 and S8). Their calculated $\gamma_{l v}$ values agreed well with the experimental values, with a maximum relative error of $\sim 10 \%$ (see Table S4). Thus, our method is a simple, fast way to estimate the AS and surface tensions of Chinese liquors using a portable device, which is useful in the field where lab platforms and analytical instruments are not available.

\section{Conclusions}

We produced U-shaped devices sprayed with a quasi-superamphiphobic coating, which we used to sort droplets with different surface tensions. Using it, we determined the surface tension and estimated the alcohol strength of Chinese liquors and showed it could be used over a hundred times to sort droplets by surface tension in the range of $33.9-72.1 \mathrm{mN} \mathrm{m}^{-1}$. Compared with tuned glass slides, our device was simpler and faster, and it did not require lengthy tuning of solid surface energy or an expensive high-speed camera. Based on our methodology and mechanism, higher resolution may be achieved, and wider range of surface tensions are possibly determined by increasing the droplet volume or changing the semi-circular arc diameter of the device. Along with our ongoing studies of the relative mechanism of energy loss of a rolling drop, we believe this method of sorting droplets and determining surface tension will lead to inexpensive, energy-efficient analytical devices for chemical assays in the field.

Supplementary Materials: The following are available online at http://www.mdpi.com/2073-4360/12/4/820/s1, Table S1: Apparent advancing and apparent receding contact angles, and the estimated roll-off angles of different water-ethanol mixtures on each of the discrete domains shown in Figure 2a-c of the main manuscript, Table S2: Total rolling distance $(\mathrm{cm})$ and relative standard deviation (RSD, \%) using the guide groove for ethanol aqueous droplets in the concentration range of $0-40 \%$, Table S3: The comparative results and relative errors (REs) between the labeled AS by suppliers and the estimated AS for 6 commercial liquor samples using the total rolling time (RT) and rolling distance (RD), Table S4: Comparative results of surface tension for the diluted liquors between the determined value by instrument and the predicted value by the fitting quadratic equation of total rolling time (RT) and rolling distance (RD), Figure S1: The wettability transformation under UV irradiation, Figure S2: The relationship between the rolling time and water droplet volume, Figure S3: The relationship between the total rolling distance and water droplet volume, Figure S4: The standard curve between AS and rolling time used to predict the ethanol volume content or AS for real liquors, Figure S5: The standard curve between AS and rolling distance used to predict the ethanol volume content or AS for real liquors, Figure S6: Track of diluted liquor droplets rolling back and forth in the U-shaped device used to estimate the ethanol volume content (or AS values) and surface tension of Chinese liquors, Figure S7: The standard curve between rolling time and surface tension used to predict the surface tension values of real liquors. The real values of surface tension for ethanol aqueous solutions were determined by the pendent drop method. Three Jinjiu liquors with the labeled AS values of $20 \%, 30 \%$, and $35 \%$ were selected for the $\gamma \mathrm{lv}$ estimation, as well as the diluted Maotai liquors with the AS values of $10.6 \%, 21.2 \%$, and $31.8 \%$, respectively, Figure S8: The standard curve between rolling distance and surface tension used to predict the surface tension values of real liquors. The real values of surface tension for ethanol aqueous solutions were determined by the pendent drop method. Three Jinjiu liquors with the labeled AS values of $20 \%, 30 \%$, and $35 \%$ were selected for the $\gamma \mathrm{lv}$ estimation, as well as the diluted Maotai liquors with the AS values of $10.6 \%, 21.2 \%$, and $31.8 \%$, respectively, Video S1: Water jetting on the quasi-superhydrophobic surface 
(AVI), Video S2: Droplet sorting using the tuned glass slide (AVI), Video S3: Standard rolling curve used to test the alcohol strength (AS) (AVI), Video S4: AS estimation of real samples (AVI).

Author Contributions: Conceptualization, C.-X.C. and D.F.; methodology, D.F. and P.-F.L.; software, D.F.; validation, J.C. and D.F.; formal analysis, D.F.; investigation, P.-F.L., X.-Z.B.; resources, L.-B.Q.; data curation, D.F.; writing-original draft preparation, Y.-P.Z.; writing-review and editing, Y.-P.Z.; visualization, D.F.; supervision, Y.-P.Z.; project administration, L.-B.Q.; funding acquisition, R.-L.L. and Y.-P.Z. All authors have read and agreed to the published version of the manuscript.

Funding: Financial support was provided from the National Nature Science Foundation of China (No. 51802082 and 51903073); the Landmark Innovation Project of Henan Institute of Science and Technology (No. 2015BZ02); the "Funds for Tai Hang Scholar" of HIST; the Science and Technology Project of Henan Province (No. 142102210047); and the Scientific Innovation Team in Henan Province (No. C20150020).

Conflicts of Interest: The authors declare no conflicts of interest.

\section{References}

1. Feng, L.; Li, S.H.; Li, Y.S.; Li, H.J.; Zhang, L.J.; Zhai, J.; Song, Y.; Liu, B.Q.; Jiang, L.; Zhu, D.B. Super-Hydrophobic Surfaces: From Natural to Artificial. Adv. Mater. 2002, 14, 1857-1860. [CrossRef]

2. Neinhuis, C.; Barthlott, W. Characterization and Distribution of Water-repellent, Self-cleaning Plant Surfaces. Ann. Bot. 1997, 79, 667-677. [CrossRef]

3. Bhushan, B.; Her, E.K. Fabrication of Superhydrophobic Surfaces with High and Low Adhesion Inspired from Rose Petal. Langmuir 2010, 26, 8207-8217. [CrossRef] [PubMed]

4. Hu, D.L.; Chan, B.; Bush, J.W.M. The hydrodynamics of water strider locomotion. Nature 2003, 424, $663-666$. [CrossRef] [PubMed]

5. Gao, X.; Jiang, L. Water-repellent legs of water striders. Nature 2004, 432, 36. [CrossRef] [PubMed]

6. Blossey, R. Self-cleaning surfaces-Virtual realities. Nat. Mater. 2003, 2, 301-306. [CrossRef]

7. Wang, S.; Liu, K.; Yao, X.; Jiang, L. Bioinspired Surfaces with Superwettability: New Insight on Theory, Design, and Applications. Chem. Rev. 2015, 115, 8230-8293. [CrossRef]

8. Vahabi, H.; Wang, W.; Movafaghi, S.; Kota, A.K. Free-Standing, Flexible, Superomniphobic Films. ACS Appl. Mater. Interfaces 2016, 8, 21962-21967. [CrossRef]

9. Peng, S.; Deng, W. A simple method to prepare superamphiphobic aluminum surface with excellent stability. Colloids Surf. A Physicochem. Eng. Asp. 2015, 481, 143-150. [CrossRef]

10. Zhang, Y.-P.; Yang, J.-H.; Li, L.-L.; Cui, C.; Li, Y.; Liu, S.-Q.; Zhou, X.-M.; Qu, L.-B. Facile Fabrication of Superhydrophobic Copper-Foam and Electrospinning Polystyrene Fiber for Combinational Oil-Water Separation. Polymers 2019, 11, 97. [CrossRef]

11. Li, Y.; Zhu, X.; Zhou, X.; Ge, B.; Chen, S.; Wu, W. A facile way to fabricate a superamphiphobic surface. Appl. Phys. A 2014, 115, 765-770. [CrossRef]

12. Li, L.; Li, B.; Dong, J.; Zhang, J. Roles of silanes and silicones in forming superhydrophobic and superoleophobic materials. J. Mater. Chem. A 2016, 4, 13677-13725. [CrossRef]

13. Xi, J.; Feng, L.; Jiang, L. A general approach for fabrication of superhydrophobic and superamphiphobic surfaces. Appl. Phys. Lett. 2008, 92, 053102-053103. [CrossRef]

14. Li, T.; Paliy, M.; Wang, X.; Kobe, B.; Lau, W.-M.; Yang, J. Facile One-Step Photolithographic Method for Engineering Hierarchically Nano/Microstructured Transparent Superamphiphobic Surfaces. ACS Appl. Mater. Interfaces 2015, 7, 10988-10992. [CrossRef] [PubMed]

15. Li, F.; Du, M.; Zheng, Q. Dopamine/Silica Nanoparticle Assembled, Microscale Porous Structure for Versatile Superamphiphobic Coating. ACS Nano 2016, 10, 2910-2921. [CrossRef] [PubMed]

16. Chu, Z.; Seeger, S. Superamphiphobic surfaces. Chem. Soc. Rev. 2014, 43, 2784-2798. [CrossRef]

17. Wu, X.; Wyman, I.; Ganwei, Z.; Lin, J.; Liu, Z.; Wang, Y.; Hu, H. Preparation of superamphiphobic polymer-based coatings via spray- and dip-coating strategies. Prog. Org. Coat. 2016, 90, 463-471. [CrossRef]

18. Ge, D.; Yang, L.; Zhang, Y.; Rahmawan, Y.; Yang, S. Transparent and Superamphiphobic Surfaces from One-Step Spray Coating of Stringed Silica Nanoparticle/Sol Solutions. Part. Part. Syst. Charact. 2014, 31, 763-770. [CrossRef]

19. Huang, J.; Lai, Y.; Pan, F.; Yang, L.; Wang, H.; Zhang, X.; Fuchs, H.; Chi, L. Multifunctional Superamphiphobic $\mathrm{TiO}_{2}$ Nanostructure Surfaces with Facile Wettability and Adhesion Engineering. Small 2014, 10, 4865-4873. [CrossRef] 
20. Milionis, A.; Fragouli, D.; Martiradonna, L.; Anyfantis, G.C.; Cozzoli, P.D.; Bayer, I.S.; Athanassiou, A. Spatially Controlled Surface Energy Traps on Superhydrophobic Surfaces. ACS Appl. Mater. Interfaces 2014, 6, 1036-1043. [CrossRef]

21. Kobayashi, T.; Shimizu, K.; Kaizuma, Y.; Konishi, S. Novel combination of hydrophilic/hydrophobic surface for large wettability difference and its application to liquid manipulation. Lab Chip 2011, 11, 639-644. [CrossRef] [PubMed]

22. Movafaghi, S.; Wang, W.; Metzger, A.; Williams, D.D.; Williams, J.D.; Kota, A.K. Tunable superomniphobic surfaces for sorting droplets by surface tension. Lab Chip 2016, 16, 3204-3209. [CrossRef] [PubMed]

23. Huang, F.; Chen, Y.; Wang, Y.; Xia, F. Tunable superamphiphobic surfaces: A platform for naked-eye ATP detection. Anal. Bioanal. Chem. 2018, 411, 4721-4727. [CrossRef] [PubMed]

24. Wang, H.; Zhou, H.; Yang, W.; Zhao, Y.; Fang, J.; Lin, T. Selective, Spontaneous One-Way Oil-Transport Fabrics and Their Novel Use for Gauging Liquid Surface Tension. ACS Appl. Mater. Interfaces 2015, 7, 22874-22880. [CrossRef]

25. Wang, Y.; Zhu, Y.; Zhang, C.; Li, J.; Guan, Z. Transparent, Superhydrophobic Surface with Varied Surface Tension Responsiveness in Wettability Based on Tunable Porous Silica Structure for Gauging Liquid Surface Tension. ACS Appl. Mater. Interfaces 2017, 9, 4142-4150. [CrossRef]

26. Liu, K.-F.; Li, P.-P.; Zhang, Y.-P.; Liu, P.-F.; Cui, C.-X.; Wang, J.-C.; Li, X.-J.; Qu, L.-B. Laboratory filter paper from superhydrophobic to quasi-superamphiphobicity: Facile fabrication, simplified patterning and smart application. Cellulose 2019, 26, 3859-3872. [CrossRef]

27. Mi, Y.X.; Zhou, Z.H.; Wang, Z.; Wang, G.W.; Yao, J. Superhydrophobic Surface Prepared by Organic-Inorganic Hybrid Material on Plasma Spraying $\mathrm{Al}_{2} \mathrm{O}_{3}+13$ wt. \%TiO $\mathrm{TiO}_{2}$ Ceramic Coating. Mater. Sci. Forum 2015, 817, 76-81. [CrossRef]

28. Teisala, H.; Tuominen, M.; Stępień, M.; Haapanen, J.; Mäkelä, J.M.; Saarinen, J.J.; Toivakka, M.; Kuusipalo, J. Wettability conversion on the liquid flame spray generated superhydrophobic $\mathrm{TiO}_{2}$ nanoparticle coating on paper and board by photocatalytic decomposition of spontaneously accumulated carbonaceous overlayer. Cellulose 2013, 20, 391-408. [CrossRef]

29. Fowkes, F.M. Attractive forces at interfaces. Ind. Eng. Chem. 1964, 12, 40-52.

30. Chhatre, S.S.; Guardado, J.O.; Moore, B.M.; Haddad, T.S.; Mabry, J.M.; McKinley, G.H.; Cohen, R.E. Fluoroalkylated Silicon-Containing Surfaces-Estimation of Solid-Surface Energy. ACS Appl. Mater. Interfaces 2010, 2, 3544-3554. [CrossRef]

31. Babu, S.R. An absolute method for the determination of surface tension of liquids using pendent drop profiles. Bull. Mater. Sci. 1986, 8, 217-224. [CrossRef]

32. Hansen, F.; Rødsrud, G. Surface tension by pendant drop. J. Colloid Interface Sci. 1991, 141, 1-9. [CrossRef]

33. Maximino, B.R. Surface Tension and Density of Binary Mixtures of Monoalcohols, Water and Acetonitrile: Equation of Correlation of the Surface Tension. Phys. Chem. Liq. 2009, 47, 475-486. [CrossRef]

34. Yilbas, B.S.; Ali, H.; Al-Sharafi, A.; Al-Aqeeli, N. Droplet dynamics on a hydrophobic surface coated with N-octadecane phase change material. Colloids Surfaces A Physicochem. Eng. Asp. 2018, 546, 28-39. [CrossRef]

35. Ahmed, G.; Sellier, M.; Jermy, M.C.; Taylor, M. Modeling the effects of contact angle hysteresis on the sliding of droplets down inclined surfaces. Eur. J. Mech.B/Fluids 2014, 48, 218-230. [CrossRef]

(C) 2020 by the authors. Licensee MDPI, Basel, Switzerland. This article is an open access article distributed under the terms and conditions of the Creative Commons Attribution (CC BY) license (http://creativecommons.org/licenses/by/4.0/). 